\title{
THE EFFECTS OF HIGH DENSITY POLYETHYLENE ADDITION TO LOW DENSITY POLYETHYLENE POLYMER ON MECHANICAL, IMPACT AND PHYSICAL PROPERTIES
}

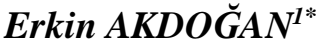

Polyethylene materials are the most widely used polymers which we encountered everywhere in our daily life. Some of the advantages of the polyethylenes are the diversity of production types, corrosion resistance, electrical insulation and recyclability. The main production methods are compression molding, transfer molding, rotational molding, injection molding, gas-assisted injection molding, extrusion and blown film extrusion techniques. It is possible to increase the mechanical properties of low density polyethylene materials by addition of high density polyethylene materials. Both polymer has same monomers but their chemical structure and bonding properties are different. Their physical properties can change with their chemical structure and bonding properties. In this study, 25\%, 50\% and 75\% by weight of high density polyethylene were added to low density polyethylene. Granules were pre-mixed with a mechanical mixer before production of the samples. Plastic injection molding machine was used for specimen preparation. Density, hardness, tensile test, three-point bend test, compression test, tear test and Izod impact tests were performed. Densities and hardness values of the polymer blends decrease by the increasing amount of low density polyethylene. In general, it was observed that the mechanical properties of the polymer blends increase as the high density polyethylene content increase.
\end{abstract}

Key words: Low density polyethylene, High density polyethylene, Density, Hardness, Tensile test, Three point bend test, Compression test, Tear test, Izod impact test

\section{Introduction}

Polymeric metarials, light weight, cheapness, insulation, sufficient mechanical properties, easy formability, decorative and ergonomic usage, chemically resistant and can be used for different purposes. Due to these properties, it has wide usage fields such as machinery, chemistry, physics, textile, industry, medicine, biochemistry and biophysics. Polymer as a word which derives from the origin of poly means multiple and mer(meros) means structure from two Greek words. Polymers consist of monomers. Monomers are the structures that can be connected to each other by covalent bonds to form large molecules. The production methods of polymers includes first the polymerisation of polymer as a

\footnotetext{
1* Department of Mechanical Engineering, University of Karamanoğlu Mehmetbey, Karaman, Turkey, (eakdogan@kmu.edu.tr) (D) https://orcid.org/0000-0001-6993-6972
} 
chemical process, after producing the desired part with mechanical and thermal process. Thermoplastic materials are in the subgroup of polymers and can be finalized by being shaped by heat and mechanical treatment. These process can be performed again and again on these materials. But their physical properties can change against heat, remolding and forming process. Injection molding, gas-assisted injection molding, extrusion, blown film extrusion, rotational molding, pressure molding and transfer molding are the main production methods of thermoplastic polymer products [1,2]. Polyethylene is a polymer with a broad range application areas in plastics industry. Polyethylene is a group in polyolefin family. Its chemical structure includes methylene $\left(\mathrm{CH}_{2}\right)$ monomers. Polyethylene materials are classified according to their density and bonding type. Low density polyethylene (LDPE), linear bonded low density polyethylene (LLDPE), medium density polyethylene (MDPE), high density polyethylene (HDPE), ultra high molecular weight polyethylene (UHMWPE) and cross-linked polyethylene (XLPE) are the six different types of polyethylenes. Some of the wide range application areas of polyethylenes are chemical containers, detergent cups, tubes, pressurized water and gas pipes, cable insulation, some automotive parts, various food storage containers, shopping bags, pochette and plastic bags, entertainment and toys. HDPE and LDPE are the most widely used polyethylene types. Both thermoplastics are suitable for injection and extrusion productions.

Polymer blends which have called as polymer alloys have been performed by researchers with mixing different polymers from many years. Productions and physical tests of HDPE-polypropylene (PP), HDPE-LLDPE and LDPE-polyamide 6 (PA6)-ethylene vinyl acetate (EVA) alloys were carried out [4]. Shebani et al. 2018 added 20\%, 40\%, 60\%, and 80\% LDPE polymer to the HDPE polymer. They performed tensile test, charpy impact test, hardness measurement and differential scanning calorimeter (DSC) tests. They found out that with the addition of LDPE, tensile strength and hardness values decreased, but the elongation at break and the toughness values increased [5]. Sarkhel et al. 2006, in their study, HDPE blended LDPE in 80/20,60/40, 40/60 and 20/80 ratios respectively to obtain polymer mixtures. They found that the melt viscosity of these mixtures decreases with the increased concentration of LDPE. Besides, they found out that increased amount of LDPE causes the deterioration in mechanical properties from the results of tensile tests. However they determined that the increasing amount of LDPE in mixture, increased the Izod impact strength values. As a result, they observed that as the LDPE ratio in HDPE polymer increased, the crystal ratio decreased in DSC analysis [6, 7].

In this study, $25 \%, 50 \%$ and $75 \%$ by mass of HDPE polymer was added to LDPE polymer. Density, hardness, Izod impact, tear, tensile, three point bending and compression tests were performed.

\section{Material and Method}

\subsection{Materials}

Two different polymer were mixed in different ratios in this study. A new polymer alloy was produced by mixing these two different polymers. LDPE polymer was used as a granular form Petilen I22-19T commercial product with a melt flow rate of $22 \mathrm{~g} / 10 \mathrm{~min}\left(190^{\circ} \mathrm{C} / 2.16 \mathrm{~kg}\right)$ of PETKIM. HDPE polymer was used as a granular form Petilen 1668 commercial product with a melt flow rate of $5.5 \mathrm{~g} / 10$ $\min \left(190{ }^{\circ} \mathrm{C} / 2.16 \mathrm{~kg}\right)$ from PETKIM. Both polymers are suitable for injection molding.

\subsection{Preparation of Samples}

The production of LDPE-HDPE mixtures, granular materials were pre-mixed with Heidolph brand, RZR 2021 model mechanical mixer. 25\%, 50\% and 75\% by mass of HDPE was added to the 
LDPE polymer. Each formula was mixed at $200 \mathrm{rpm}$ for 10 minutes. The samples were dried in the oven at $60{ }^{\circ} \mathrm{C}$ for 4 hours to remove moisture. Specimens were prepared in a single screw plastic injection molding machine (diameter: $35 \mathrm{~mm}$, L/D ratio: 30, clamping force: $700 \mathrm{kN}$ ). Mixtures were injected into mold at 170-180-190-200 ${ }^{\circ} \mathrm{C}$ temperatures from feeding zone to nozzle zone. Mechanical mixer, oven and plastic injection molding machine are shown in Figure 1.

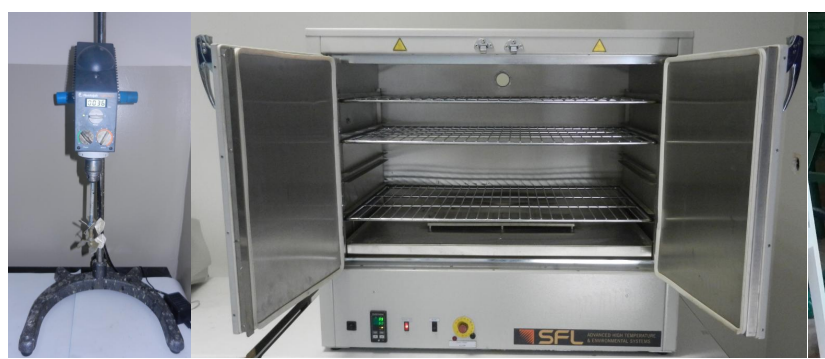

(a)

(b)

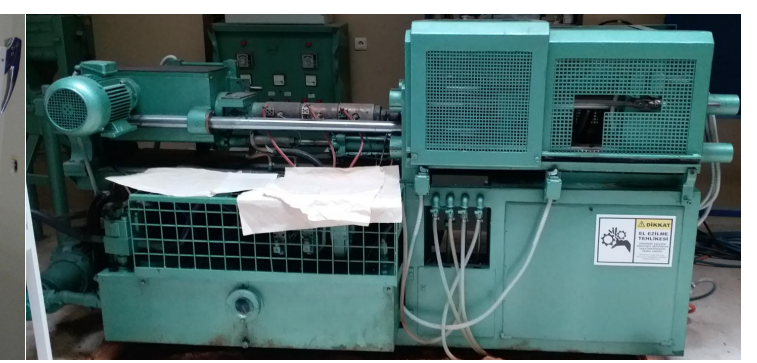

(c)

Figure 1. Equipment and machines used in production a) mechanical mixer, b) oven and c) plastic injection machine

Mixing ratios by weight of the samples are given in Table 1. Thirty specimen groups were produced from each formulas. The specimen group includes tensile test, flexural test, tear test, conical calorimeter test, compression test, notched and unnotched Izod impact test specimens (Figure 2).

Table 1. Mixing ratios of HDPE-LDPE blends

\begin{tabular}{ccccc}
\hline Specimen & Code & LDPE (\%) & HDPE (\%) & Total (\%) \\
\hline LDPE & LDPE & 100 & - & 100 \\
LDPE3-HDPE1 & L3H1 & 75 & 25 & 100 \\
LDPE1-HDPE1 & L1H1 & 50 & 50 & 100 \\
LDPE1-HDPE3 & L1H3 & 25 & 75 & 100 \\
HDPE & HDPE & - & 100 & 100 \\
\hline
\end{tabular}

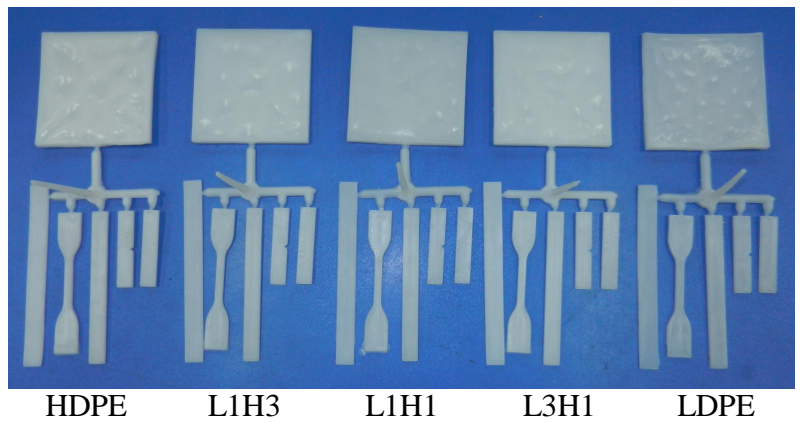

Figure 2. The produced samples in the plastic injection molding machine

\subsection{Tests and Characterizations}

All samples were stored in Nüve brand TK252 model conditioning cabinet at $23{ }^{\circ} \mathrm{C}$ and $50 \%$ relative humidity for 40 hours according to ASTM D618 standard before tests (Figure 3). Tests were performed at $23{ }^{\circ} \mathrm{C}$ and $50 \%$ relative humidity.

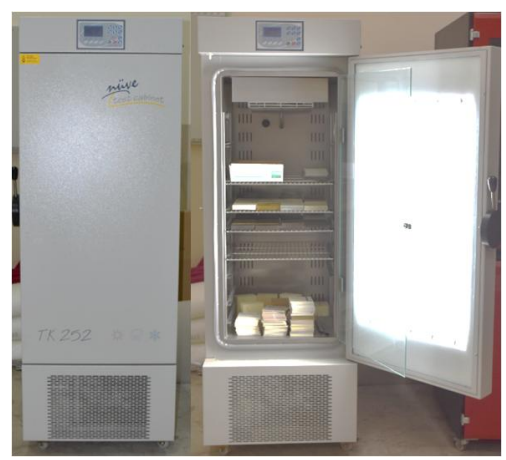




\section{Figure 3. Nüve TK 252 conditioning unit}

The density measurement was made from 6 samples from each formulas. The mass and volumes were measured and the density of the samples were calculated by dividing the mass by volume according to ASTM D792 standard. Three-point bending samples were used for density measurement (Figure 4). Hardness measurements were carried out on 6 samples in X.F Shore-D hardness tester (Figure 5) according to ASTM D2240 standard.

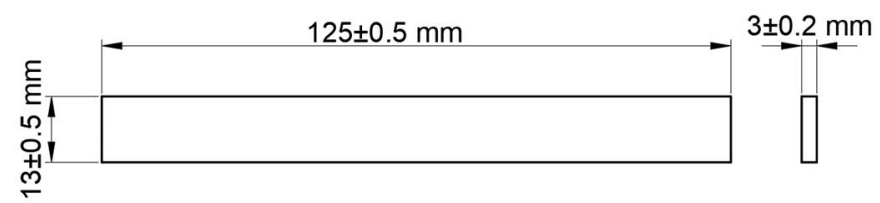

Figure 4. The dimensions of three-point bending specimen [3]

Figure 5. X.F Shore-D durometer

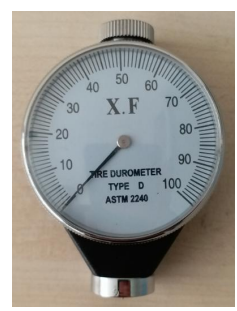

Impact strength properties were determined with pendulum impact test machine. Izod impact resistance test was performed at Ceast Resil Impactor device (Figure 6) according to ASTM D256 standard. 6 samples were tested from each mixture with $7.5 \mathrm{~J}$ to $25 \mathrm{~J}$. The dimensions of the specimens are shown in Figure 7. The size of notch is $2.54 \mathrm{~mm}$ depth with an angle of $45^{\circ}$ according to ASTM D256 standard.

Figure 6. Ceast Resil impactor test device [3]
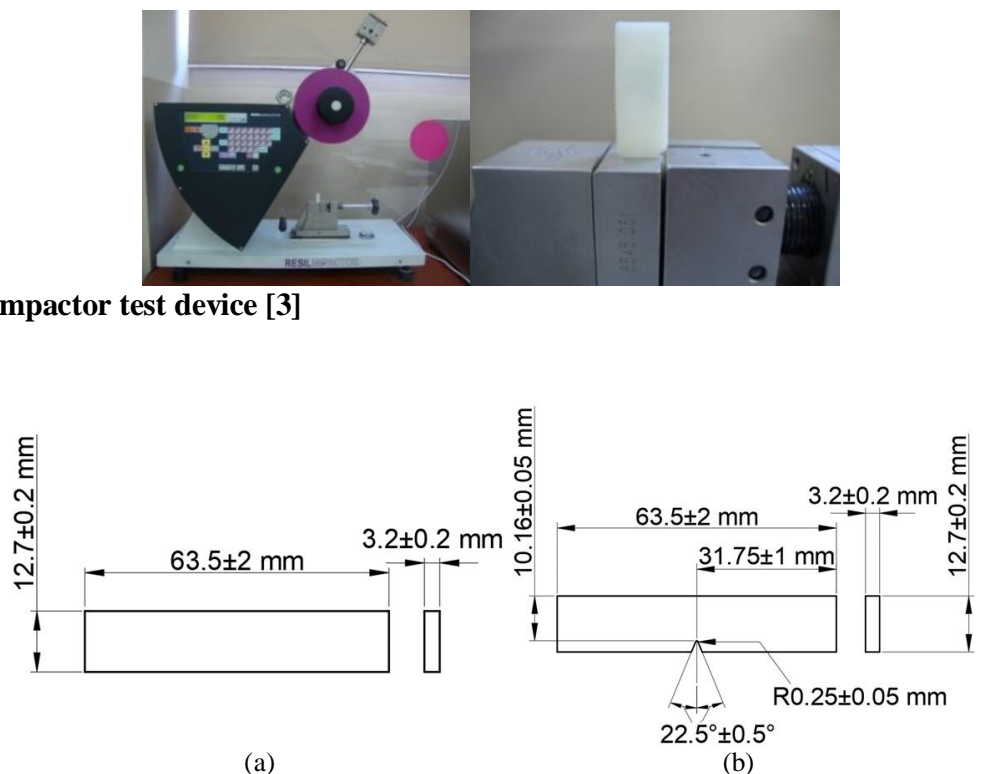

Figure 7. The dimensions of Izod impact test specimens (a) unnotched and (b) notched [3]

Tear strength test was performed on 6 samples from each mixture according to ASTM D624 (Type-T) standard. The tests were performed on Shimadzu brand AGS-X $100 \mathrm{kN}$ model $100 \mathrm{kN}$ load cell equipped static tensile-compression tester (Figure 8) with a tensile speed of $50 \pm 5 \mathrm{~mm} / \mathrm{min}$. The dimensions of the tear test specimens were given in Figure 9. Tear strengths of mixtures were calculated from tear tests. 


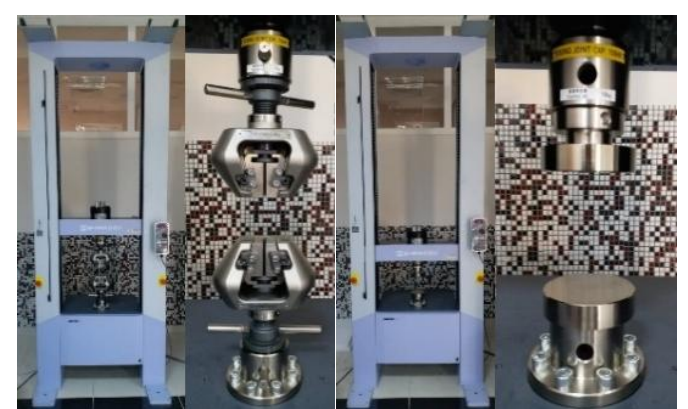

Figure 8. Shimadzu AGS-X 100 kN tensile-compression test device

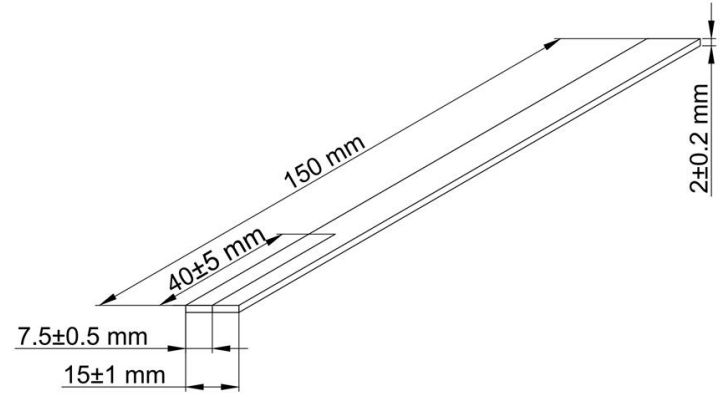

Figure 9. The dimensions of tear test specimen [3]

Tensile tests were performed in Shimadzu brand AGS-X $100 \mathrm{kN}$ model $100 \mathrm{kN}$ load cell equipped static tensile-compression test device at $50 \pm 5 \mathrm{~mm} / \mathrm{min}$ tensile speed according to ASTM D638 (TypeIV) standard. The dimensions of the tensile test specimens are given in Figure 10. Six tensile test specimen were tested from each formulas. Tensile strength, rupture strength, modulus of elasticity according to tensile condition, elongation at break and toughness values of the material were calculated from the tensile tests.

Figure 10. The dimensions of tensile test specimen [3]

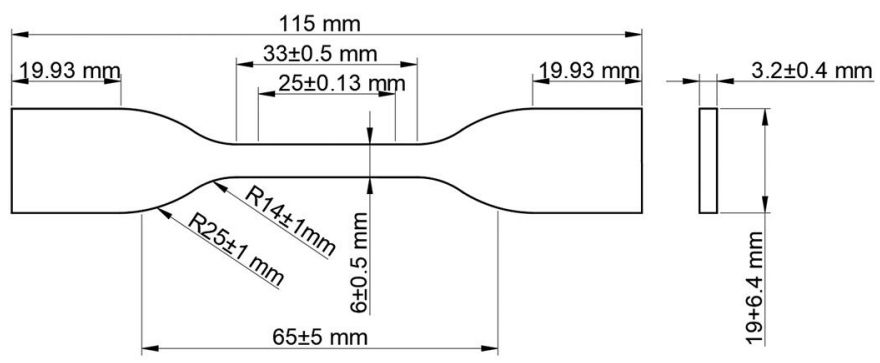

Three-point bend tests were performed in Instron 8801 model $50 \mathrm{kN}$ load capacity dynamic tensile and compression test device according to ASTM D790 standard with crosshead speed of $1.4564 \mathrm{~mm} / \mathrm{min}$ (Figure 11). The sizes of the three point bend test specimen is given in Figure 4 and six specimen were tested from each formula. Bending strength and flexural modulus according to bending condition values were calculated from the tests. $5 \%$ strain were taken into account to find the flexural strength values.

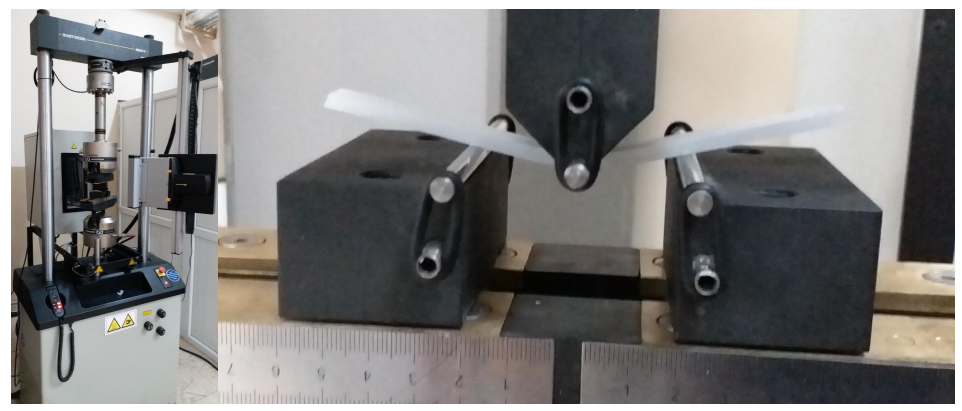

Figure 11. Instron 8801 dynamic tensile-compression test device 
Compressive tests were performed in Shimadzu brand AGS-X $100 \mathrm{kN}$ model $100 \mathrm{kN}$ load cell equipped static tensile testing machine was used with crosshead speed at $1.3 \mathrm{~mm} / \mathrm{min}$ according to ASTM D695 standard. The compressive test plates were shown in Figure 8. The sizes of the compression test specimen less than $3.2 \mathrm{~mm}$ thickness is given in Figure 12 and six specimen were tested from each formulas. Compressive strength, yield stress in compression and compressive modulus values were calculated according to the compression state. $10 \%$ deformation values were taken into account of the specimens for compressive strength values. The compressive modulus of HDPE and LDPE were calculated from the slope of the linear region in stress-strain curve.

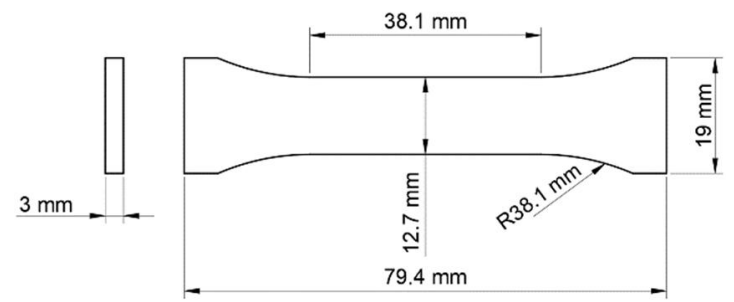

Figure 12. The dimensions of compressive test specimen

\section{Experimental Results and Discussion}

\subsection{Density}

The results of the density measurements; mean values, maximum and minimum ranges were given in Figure 13(a). The mean and standard deviation of the density values were given in Table 2. The addition of LDPE to the HDPE polymer increase the density values. The density of pure LDPE was $0.888 \mathrm{~g} / \mathrm{cm}^{3}$ while the density of pure HDPE was $0.951 \mathrm{~g} / \mathrm{cm}^{3}$. The addition of $25 \%$ mass of HDPE to LDPE polymer increases the density by $2 \%$ to $0.905 \mathrm{~g} / \mathrm{cm}^{3}$. Increasing amount of HDPE addition to LDPE polymer $50 \%$ and $\% 75$ mass increases the density by $\% 3$ and $\% 4$ to $0.913 \mathrm{~g} / \mathrm{cm}^{3}$ and $0.922 \mathrm{~g} / \mathrm{cm}^{3}$ respectively.

\subsection{Hardness}

Hardness value of the polymers plays key role in their usage areas. The meaning of the hardness is resistance of a material to deformation, indentation, penetration and scratching. The hardness values of polymers vary depending on their crystal phases. HDPE is more crystalline polymer (51\%) than LDPE polymer (38\%) [8]. The more crystalline phases bring more rigid and hard physical properties. [5]. This results are the evidence of this explanation. It has been observed that LDPE polymer hardness about 42.9 Shore-D and HDPE was 63.9 Shore-D in the hardness test. Figure 13(b) shows the average hardness values, the highest and the lowest ranges. Mean hardness and standard deviation values are given in Table 2. 25\% mass of HDPE addition significantly increase the hardness values of LDPE by $34 \%$ to 57.4 Shore-D. $\% 50$ mass of HDPE addition increase the hardness values of HDPE by $35 \%$ to 57.9 Shore-D. Further addition of 75\% mass of HDPE to LDPE polymer increase the hardness values by $44 \%$ to 61.6 Shore-D. The hardness value of the LDPE polymer was much lower than HDPE polymer. It was observed that significant change in the hardness values by adding HDPE to LDPE polymer. 


\subsection{Izod Impact Test}

In spite of hammer value reached $25 \mathrm{~J}$, unnotched Izod impact specimens couldn't be broken. The hammer tilted the sample and passed the other side. In the notched Izod impact experiments, no breakage was observed 25\% by mass of HDPE in LDPE polymer and pure LDPE. That's because of the soft and more flexible segments of LDPE in LDPE-HDPE blend. 25\% LDPE and 50\% LDPE were added to the specimens were broken with a 7.5 J hammer (Figure 13(c)). Due to HDPE more crystalline than LDPE polymer and more co-monomer decrease the crystal orientation. This disrupts the impact properties of the polymer [9]. The Izod impact strength of notched pure HDPE was found $8.5 \mathrm{~kJ} / \mathrm{m}^{2}$. The addition of $75 \%$ and $50 \%$ mass of HDPE to LDPE polymer decrease the Izod impact strength values compared to HDPE polymer by $\% 11$ and $\% 20$ to $7.6 \mathrm{~kJ} / \mathrm{m}^{2}$ and $6.8 \mathrm{~kJ} / \mathrm{m}^{2}$ respectively. Mean Izod impact strength values and standard deviation values are given in Table 2.

\subsection{Tear Test}

The highest and lowest ranges of tear strength values of the blends are given in Figure 13(d). Mean tear strength and standard deviation values are given in Table 2. The tear strength value of pure LDPE was found $45 \mathrm{~N} / \mathrm{mm}$ and pure HDPE was found $132 \mathrm{~N} / \mathrm{mm}$. The addition of $25 \%$ HDPE by mass to LDPE polymer increase tear strength values by $16 \%$ to $52 \mathrm{~N} / \mathrm{mm}$ compared to LDPE. It was observed by the addition of $\% 75$ HDPE to LDPE polymer increased by $28 \%$ to $57 \mathrm{~N} / \mathrm{mm}$. The addition of $50 \%$ HDPE by mass to the LDPE polymer decreased to the lowest tear strength value by $52 \%$ to $21 \mathrm{~N} / \mathrm{mm}$. In general, it has been observed that HDPE addition to LDPE polymer increase the tear strength values. In contrast to this the addition of LDPE to HDPE polymer decreases the tear strength values remarkable except the addition of both polymer 50\% weight percentage significantly decreases the tear strength values. Because of the branching network of LDPE more complicated than HDPE polymer [5-9]. This detoriates the tearing properties.

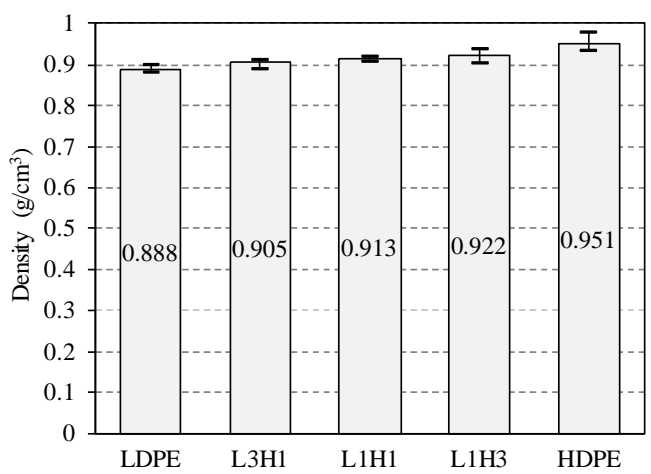

(a)

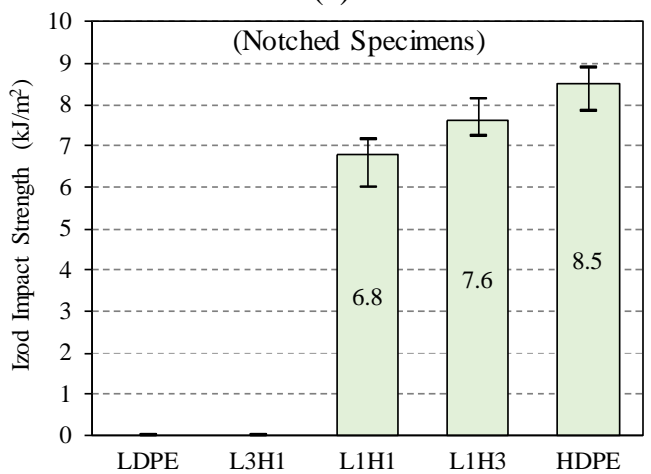

(c)

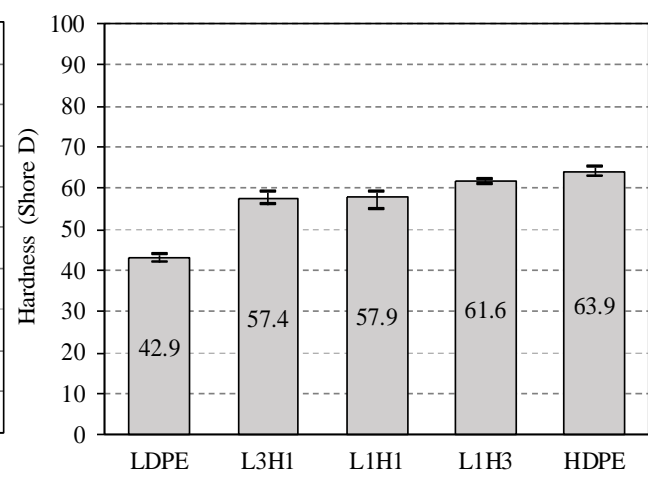

(b)

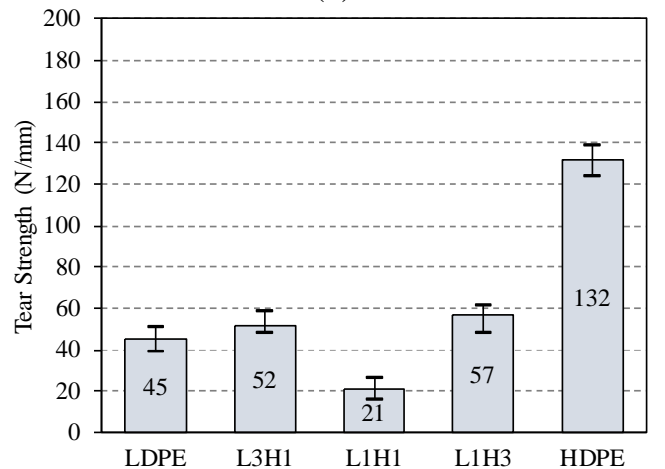

(d)

Figure 13. (a) Density, (b) hardness, (c) Izod impact strength and (d) tear strength values of LDPE-HDPE blends 
Table 2. Density, hardness, Izod impact strength and tear strength values of LDPE-HDPE blends

\begin{tabular}{cccccc}
\hline \multirow{2}{*}{ Code } & \multirow{2}{*}{$\begin{array}{c}\text { Density } \\
\left(\mathbf{g} / \mathbf{c m}^{\mathbf{3}}\right)\end{array}$} & $\begin{array}{c}\text { Hardness } \\
\text { (Shore D) }\end{array}$ & \multicolumn{2}{c}{ Izod Impact Strength $\left(\mathbf{k J} / \mathbf{m}^{\mathbf{2}}\right)$} & \multirow{2}{*}{$\begin{array}{c}\text { Tear Strength } \\
\text { (N/mm) }\end{array}$} \\
\cline { 1 - 1 } LDPE & $0.888 \pm 0.007$ & $42.9 \pm 0.8$ & - & - & $45 \pm 5$ \\
L3H1 & $0.905 \pm 0.008$ & $57.4 \pm 1.1$ & - & - & $52 \pm 4$ \\
L1H1 & $0.913 \pm 0.004$ & $57.9 \pm 1.7$ & - & $6.8 \pm 0.5$ & $21 \pm 5$ \\
L1H3 & $0.922 \pm 0.014$ & $61.6 \pm 0.5$ & - & $7.6 \pm 0.4$ & $57 \pm 7$ \\
HDPE & $0.951 \pm 0.016$ & $63.9 \pm 0.9$ & - & $8.5 \pm 0.4$ & $132 \pm 7$ \\
\hline
\end{tabular}

\subsection{Tensile Test}

Tensile test is important to characterize the material mechanical behaviors from the stress-strain curves under tension state. This test was revealed to find suitable application and optimum usage ratio of LDPE and HDPE polymer blends. The tensile test curves of the LDPE-HDPE samples were given in Figure 14. Mean values and standard deviation values of tensile strength, rupture strength, modulus of elasticity, elongation at break and toughness values of the composites were given in Table 3.

The average, highest and lowest range values of tensile strengths were shown in Figure 15(a). It was observed that the tensile strength of LDPE polymer was found 7.7 MPa and HDPE polymer was $30.6 \mathrm{MPa}$. The addition of $25 \%$ mass of HDPE to LDPE polymer increases the tensile strength by $121 \%$ to $17 \mathrm{MPa}$. Furthermore, it was seen that $50 \%$ and $75 \%$ addition of HDPE to LDPE polymer decreases tensile strength by $142 \%$ and $213 \%$ to $18.6 \mathrm{MPa}$ and $24.1 \mathrm{MPa}$ values respectively.

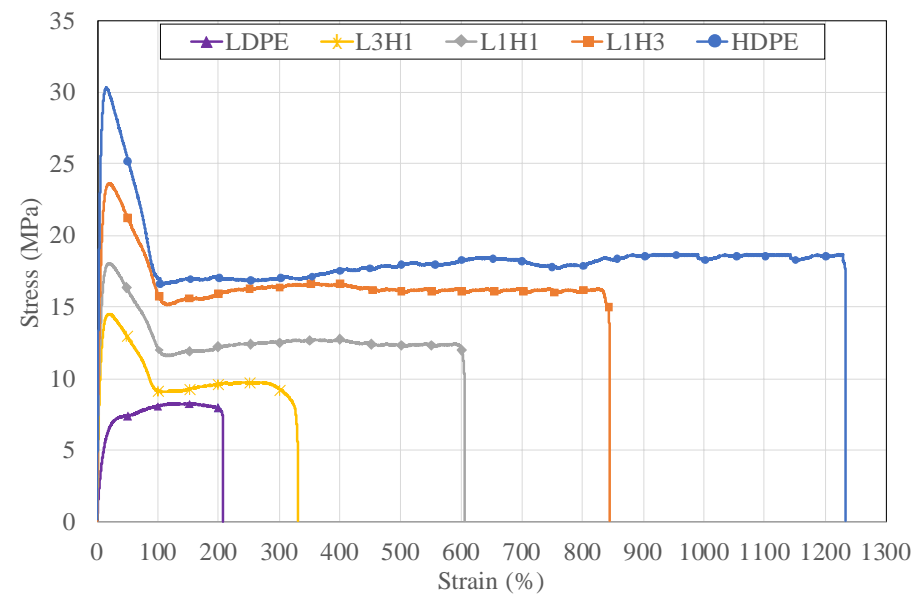

Figure 14. Stress-Strain curves of LDPE-HDPE blends

Table 3. Tensile test results of LDPE-HDPE blends

\begin{tabular}{cccccc}
\hline Code & $\begin{array}{c}\text { Tensile Strength } \\
(\mathbf{M P a})\end{array}$ & $\begin{array}{c}\text { Rupture Strength } \\
(\mathbf{M P a})\end{array}$ & $\begin{array}{c}\text { Elasticity Modulus } \\
(\mathbf{M P a})\end{array}$ & $\begin{array}{c}\text { Elongation at Break } \\
(\mathbf{\%})\end{array}$ & $\begin{array}{c}\text { Thoughness } \\
\left(\mathbf{J} / \mathbf{m m}^{\mathbf{3}}\right)\end{array}$ \\
\hline LDPE & $7.7 \pm 0.4$ & $7.1 \pm 0.3$ & $102 \pm 12$ & $208 \pm 12$ & $1.6 \pm 0.2$ \\
L3H1 & $17 \pm 1.5$ & $8.7 \pm 0.6$ & $305 \pm 20$ & $346 \pm 28$ & $3.3 \pm 0.4$ \\
L1H1 & $18.6 \pm 0.6$ & $12.5 \pm 0.3$ & $448 \pm 38$ & $670 \pm 40$ & $6.9 \pm 0.6$ \\
L1H3 & $24.1 \pm 1.1$ & $14.8 \pm 0.7$ & $523 \pm 31$ & $878 \pm 57$ & $10.1 \pm 0.6$ \\
HDPE & $30.6 \pm 1.3$ & $17.7 \pm 0.6$ & $920 \pm 46$ & $1249 \pm 42$ & $23.1 \pm 1.2$ \\
\hline
\end{tabular}

Same manner was observed in rupture strengths, the addition of HDPE to LDPE polymer were significantly increased the rupture strengths (Figure 15(b)). It has been determined that the rupture strength of LDPE was 7.1 MPa and HDPE was 17.7 MPa. The addition of HDPE by $25 \%$ mass to LDPE polymer increased the rupture strength by $23 \%$ to $8.7 \mathrm{MPa} .50 \%$ and $75 \%$ mass of HDPE addition to LDPE polymer were increased this value by $76 \%$ and $108 \%$ to $12.5 \mathrm{MPa}$ and $14.8 \mathrm{MPa}$ values respectively.

The elasticity modulus of LDPE and HDPE polymer were observed $102 \mathrm{MPa}$ and $920 \mathrm{MPa}$ respectively. 25\% addition of HDPE to LDPE polymer was increased the elasticity modulus 
significantly by $199 \%$ to $305 \mathrm{MPa}$. It was observed that $50 \%$ of HDPE addition to LDPE polymer was increased by $339 \%$ to $448 \mathrm{MPa}$. Furthermore, the addition of $75 \%$ HDPE to LDPE polymer increased the elasticity modulus by $413 \%$ to $523 \mathrm{MPa}$ (Figure $15(\mathrm{c})$ ).

The elongation at break values of LDPE polymer was around 208\%, while the elongation at break of HDPE polymer was $1249 \%$ (Figure 15(d)). By the addition of 25\% HDPE to LDPE polymer, this value was seen to increase by $66 \%$ to $346 \%$. The addition of $50 \%$ and $75 \%$ HDPE to LDPE polymer increased the elongation at break values by $222 \%$ and $322 \%$ to $670 \%$ and $878 \%$ respectively.

The thoughness values were observed from the tensile test curves. The areas under curves were calculated. The highest and the lowest ranges and mean values were given in Figure 15(e). Pure LDPE polymer thoughness value was calculated $1.6 \mathrm{~J} / \mathrm{mm}^{3}$ and HDPE polymer was $23.1 \mathrm{~J} / \mathrm{mm}^{3}$. It was observed that the addition of $25 \%$ mass of HDPE to LDPE polymer increase by $106 \%$ to $3.3 \mathrm{~J} / \mathrm{mm}^{3}$, $50 \%$ of HDPE to LDPE increases by $331 \%$ to $6.9 \mathrm{~J} / \mathrm{mm}^{3}$ and $75 \%$ of HDPE to LDPE increase by $531 \%$ to $10.1 \mathrm{~J} / \mathrm{mm}^{3}$.

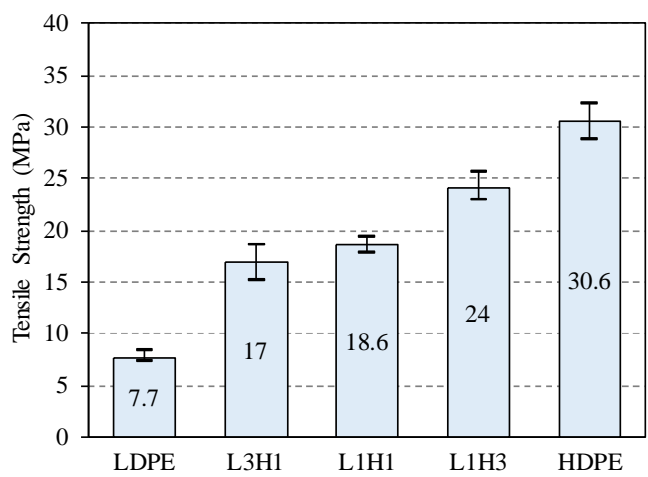

(a)

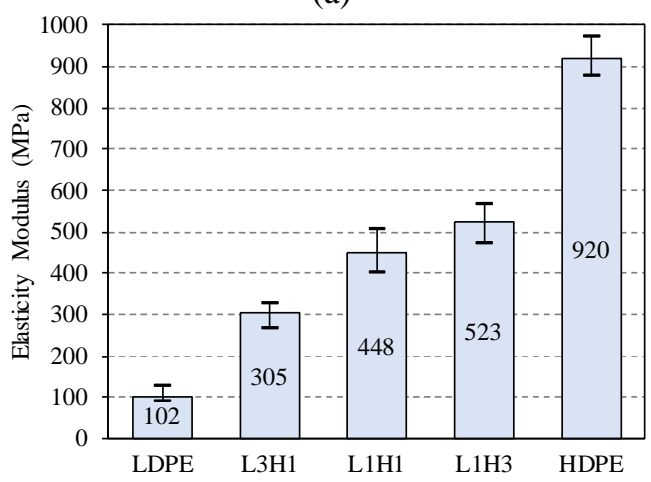

(c)

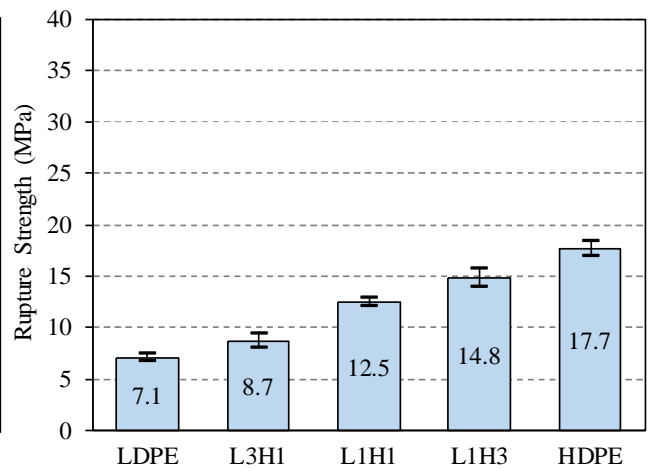

(b)

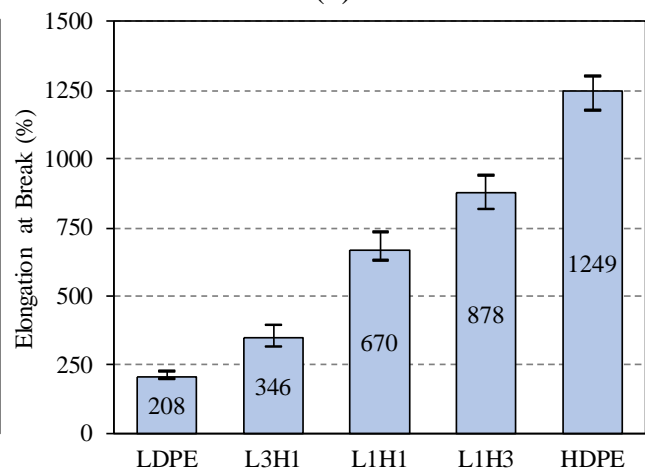

(d)

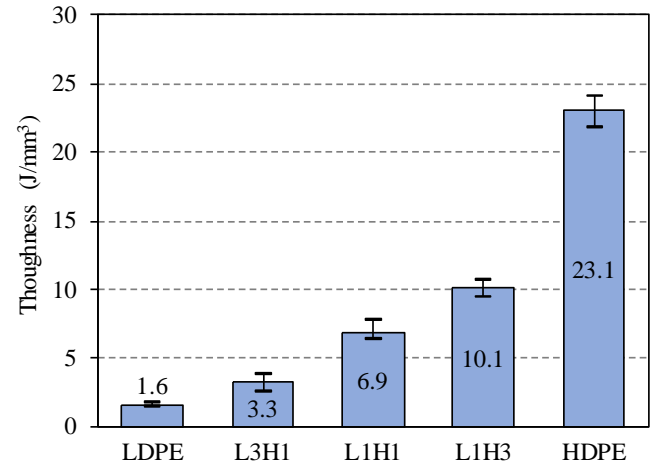

(e)

Figure 15. (a) Tensile strength, (b) rupture strength, (c) elasticity modulus, (d) elongation at break and (e) thoughness values of LDPE-HDPE blends 


\subsection{Three Point Bend Test}

The mean and standard deviation values of flexural strength and flexural modulus of composites were given in Table 4. The addition of HDPE to LDPE polymer increased the flexural strength and flexural modulus values according to bending state.

Table 4. Three point bend test results of LDPE-HDPE blends

\begin{tabular}{ccc}
\hline Code & $\begin{array}{c}\text { Flexural Strength } \\
\text { (MPa) }\end{array}$ & $\begin{array}{c}\text { Flexural Modulus } \\
\text { (MPa) }\end{array}$ \\
\hline LDPE & $7.8 \pm 0.5$ & $345 \pm 19$ \\
L3H1 & $10.9 \pm 0.7$ & $455 \pm 34$ \\
L1H1 & $13.3 \pm 0.8$ & $558 \pm 29$ \\
L1H3 & $17.1 \pm 1.2$ & $875 \pm 28$ \\
HDPE & $24.3 \pm 0.9$ & $1109 \pm 51$ \\
\hline
\end{tabular}

The average, highest and lowest range values of flexural strengths are shown in Figure 16(a). The flexural strength value of LDPE polymer was observed 7.8 MPa and HDPE polymer was 24.3 MPa. $25 \%$ by mass of HDPE addition to LDPE polymer was increased flexural strength value by $40 \%$ to 10.9 MPa. By mass of 50\% and 75\% additon of HDPE to LDPE polymer increased flexural strength by $71 \%$ and $119 \%$ to 13.3 and $17.1 \mathrm{MPa}$ respectively.

The flexural modulus of LDPE polymer was calculated $345 \mathrm{MPa}$ and HDPE polymer was 1109 $\mathrm{MPa}$. The addition $25 \%$ by mass of HDPE to LDPE polymer increased the flexural modulus by $50 \%$ to $455 \mathrm{MPa}, 50 \%$ mass of HDPE addition increased by $97 \%$ to $558 \mathrm{MPa}$ and $75 \%$ addition increased by $241 \%$ to $875 \mathrm{MPa}$ (Figure 16(b)). It was found that increasing amount of HDPE addition to LDPE polymer were increased the flexural strength and flexural modulus.

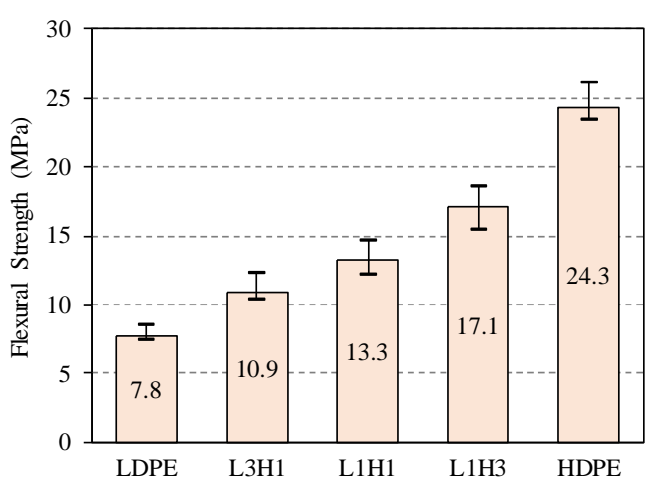

(a)

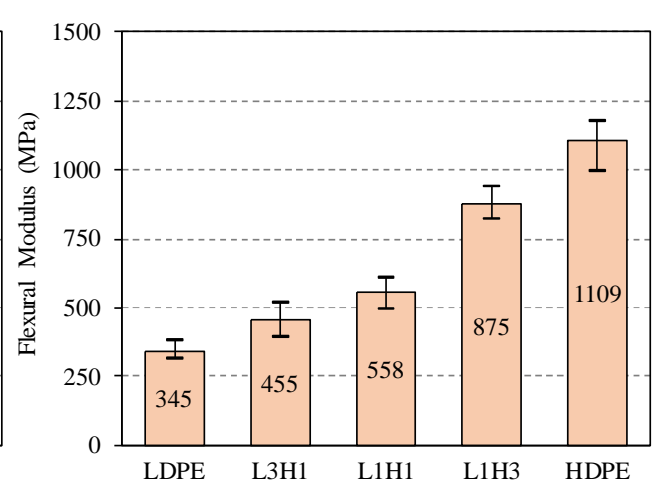

(b)

Figure 16. (a) Flexural strength and (b) flexural modulus values of LDPE-HDPE blends

\subsection{Compressive Strength Test}

Compressive strength, compressive yield strength and compressive modulus of LDPE-HDPE blends mean and standard deviation values were given in Table 5. The compressive strength value of LDPE was found 10.7 MPa and HDPE was $23 \mathrm{MPa}$. The addition of 25\% HDPE to LDPE polymer was increased the compressive strength values of composite by $50 \%$ to $16.1 \mathrm{MPa} .50 \%$ and $75 \%$ addition of HDPE polymer to LDPE polymer were increased by $60 \%$ and $63 \%$ to $17.1 \mathrm{MPa}$ and $17.4 \mathrm{MPa}$ respectively (Figure 17(a)).

Compressive yield strength values of LDPE and HDPE were calculated 4.2 $\mathrm{MPa}$ and $9 \mathrm{MPa}$ respectively. The addition of 25\% HDPE to LDPE polymer increased by $126 \%$ to $9.5 \mathrm{MPa}$. $50 \% \mathrm{HDPE}$ increased $76 \%$ to $7.4 \mathrm{MPa}$ and $75 \%$ HDPE increased by $157 \%$ to $10.8 \mathrm{MPa}$ (Figure 17 (b)). 
The highest and lowest ranges and mean values of compressive modulus were shown in Figure 17(c). The compressive modulus of LDPE and HDPE were found $185 \mathrm{MPa}$ and $710 \mathrm{MPa}$ respectively. Addition of 25\% mass of HDPE to LDPE polymer increased the compressive modulus by $66 \%$ to 307 MPa. 50\% HDPE addition increased by $107 \%$ to $383 \mathrm{MPa}$. Furthermore $75 \%$ addition of HDPE to LDPE polymer increased by $\% 130$ to $426 \mathrm{MPa}$.

Table 5. Compression test results of LDPE-HDPE blends

\begin{tabular}{cccc}
\hline Code & $\begin{array}{c}\text { Compressive Strength } \\
(\mathbf{M P a})\end{array}$ & $\begin{array}{c}\text { Compressive Yield Strength } \\
(\mathbf{M P a})\end{array}$ & $\begin{array}{c}\text { Compressive Modulus } \\
(\mathbf{M P a})\end{array}$ \\
\hline LDPE & $10.7 \pm 0.7$ & $4.2 \pm 0.4$ & $185 \pm 12$ \\
L3H1 & $16.1 \pm 0.3$ & $9.5 \pm 0.6$ & $307 \pm 37$ \\
L1H1 & $17.1 \pm 0.7$ & $7.4 \pm 0.5$ & $383 \pm 36$ \\
L1H3 & $17.4 \pm 0.8$ & $10.8 \pm 0.6$ & $426 \pm 27$ \\
HDPE & $23 \pm 0.8$ & $9 \pm 0.3$ & $710 \pm 40$ \\
\hline
\end{tabular}

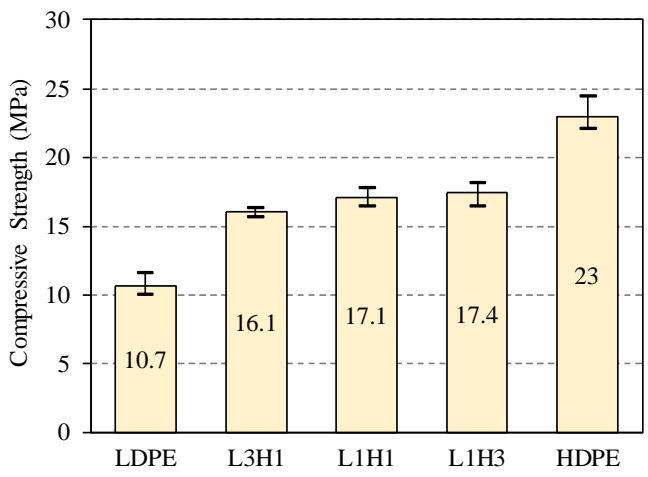

(a)

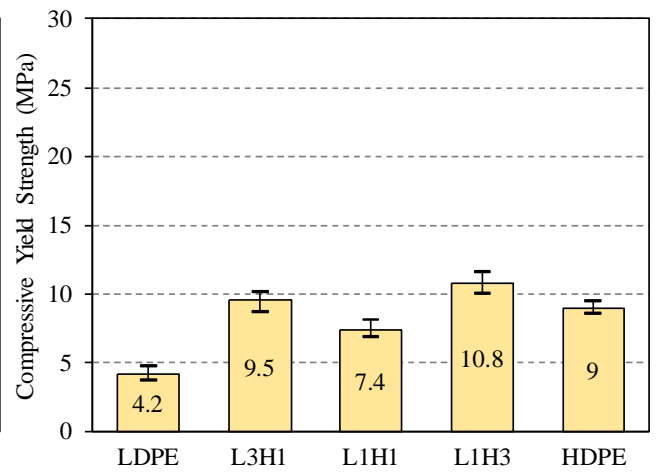

(b)

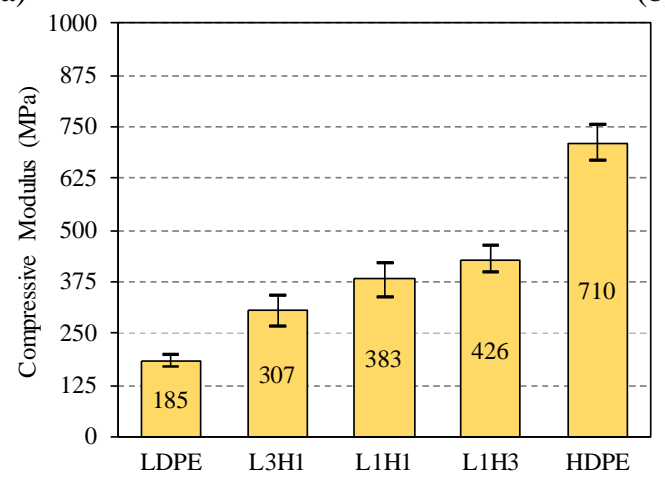

(c)

Figure 17. (a) Compressive strength, (b) compressive yield strength and (c) compressive modulus values of LDPE-HDPE blends

\section{Conclusions}

In this study, it was carried out that mixing the low density and high density polyethylene in different ratios. The production method of the samples were performed by plastic injection machine. HDPE polymers were added to LDPE polymers in $25 \%, 50 \%, 75 \%$ by mass and some physical and mechanical tests were performed. As a result of the studies, the following conclusions were drawn.

- It was found out that the addition of HDPE to LDPE polymer increase the density, hardness and tear strength values. In contrast, the addition of the LDPE to HDPE polymer decrease these values.

- In Izod impact tests, although the hammer energy increased to $25 \mathrm{~J}$, all unnotched specimens couldn't be broken. HDPE, L1H3 and and L1H1 specimens were broken in notched Izod impact tests. The addition of $75 \%$ and $50 \%$ HDPE to LDPE polymer decrease the Izod impact strength values compared to pure HDPE polymer. 
- It was found that the tensile curves obtained from the tensile test were in accordance with the pure LDPE and pure HDPE polymer tensile characteristics.

- Tensile strength, rupture strength, elongation at break, toughness and modulus of elasticity values were increased by adding HDPE to LDPE polymer from the results of the tensile tests.

- Flexural strength and flexural modulus values of the composites increased by the addition of HDPE polymer to LDPE polymer.

- It was observed that the addition of HDPE to LDPE polymer increases the compressive strength, compressive yield strength and compressive modulus. 25\% and 75\% of LDPE addition increase the compressive yield strength values above pure HDPE.

- In contrast to all results the addition of LDPE to HDPE polymer decreases the physical and mechanical properties of HDPE polymer.

- Thermal and combustion tests of these polymer blends will be performed in the next study.

\section{Acknowledgement}

Author would like to thank both institutions for using Pamukkale University, Mechanical Engineering Laboratories and Karamanoğlu Mehmetbey University, Mechanical Engineering Laboratories. This study was oral presented proceeding in UMTK 2019 congress.

\section{References}

[1] Saçak, M., Polimer Kimyası (Polymer Chemistry), Gazi Kitabevi, Ankara, TR, 2008.

[2] Akkurt, S., Plastik Malzeme Bilimi Teknolojisi ve Kalıp Tasarımı (Plastic Material Science Technology and Mold Design), Birsen Yayınevi, İstanbul, TR, 2007.

[3] Akdoğan, E. and Yurtseven, R. (2016). The Effects of Ammonium Polyphosphate and Boron Containing Flame Retardants on Mechanical Properties of Thermoplastic Polyurethane Materials. 16th International Materials Symposium (IMSP'2016), Denizli, TR, 262-270.

[4] Taşdemir, M., Polimer Karışımları ve Uygulamaları (Polymer Blends and Applications), Seçkin Yayıncılık, Ankara, TR, 2016.

[5] Shebani, A., Klash, A., Elhabishi, R., Abdsalam, S., Elbreki, H. and Elhrari, W., (2018). The Influence of LDPE Content on the Mechanical Properties of HDPE/LDPE Blends, Research \& Development in Material Science, 7(5), 1-7.

[6] Sarkhel, G., Banerjee, A. and Bhattacharya, P., (2006). Rheological and Mechanical Properties of LDPE/HDPE Blend, Polymer-Plastics Technology and Engineering, 45, 713-718.

[7] Cho, K., Lee, B.H., Hwang, K., Lee, H., and Choe, S., (1998). Rheological and Mechanical Properties in Polyethylene Blends, Polymer Engineering and Science, 38(12), 1969-1975.

[8] Li, D., Zhou, L., Wang, X., and Yang, X., (2019). Effect of Crystallinity of Polyethylene with Different Densities on Breakdown Strength and Conductance Property, Materials, 12(11), 17461758 .

[9] Ren, Y., Shi, Y., Yao, X., Tang, Y., and Liu, L.Z., (2019). Different dependence of tear strength on film orientation of LLDPE made with different co-monomer. Polymers, 11(3), doi:10.3390/polym11030434. 
[10] ASTM D256, Standard Test Methods for Determining the Izod Pendulum Impact Resistance of Plastics, ASTM International, West Conshohocken, PA, U.S.A., (2013).

[11] ASTM D618, Standard Practice for Conditioning Plastics for Testing, ASTM International, West Conshohocken, PA, U.S.A., (2013).

[12] ASTM D624, Standard Test Method for Tear Strength of Conventional Vulcanized Rubber and Thermoplastic Elastomers, ASTM International, West Conshohocken, PA, U.S.A., (2012).

[13] ASTM D638, Standard Test Method for Tensile Properties of Plastics, ASTM International, West Conshohocken, PA, U.S.A., (2014).

[14] ASTM D790, Standard Test Methods for Flexural Properties of Unreinforced and Reinforced Plastics and Electrical Insulating Materials, ASTM International, West Conshohocken, PA, U.S.A., (2017).

[15] ASTM D792, Standard Test Methods for Density and Specific Gravity (Relative Density) of Plastics by Displacement, ASTM International, West Conshohocken, PA, U.S.A., (2013).

[16] ASTM D2240, Standard Test Method for Rubber Property-Durometer Hardness, ASTM International, West Conshohocken, PA, U.S.A., (2015). 